\title{
Cross-Dehydrogenative Coupling of Tertiary Amines and Terminal Alkynes Catalyzed by Copper Nanoparticles on Zeolite
}

\author{
Francisco Alonso, ${ }^{\mathrm{a}, *}$ Adrián Arroyo, ${ }^{\mathrm{a}}$ Iris Martín-García ${ }^{\mathrm{a}}$ and Yanina Moglie ${ }^{\mathrm{a}, \uparrow}$ \\ a Instituto de Síntesis Orgánica (ISO) and Departamento de Química Orgánica, Facultad de Ciencias, \\ Universidad de Alicante, Apdo. 99, 03080 Alicante, Spain \\ Fax: (+34) 965903549; phone: (+34) 965909614; e-mail: falonso@ua.es \\ $\dagger$ Present address: Departamento de Química, Instituto de Química del Sur (INQUISUR-CONICET), Universidad \\ Nacional del Sur, Avenida Alem 1253, 8000 Bahía Blanca, Argentina
}

Received: ((will be filled in by the editorial staff))

Supporting information for this article is available on the WWW under http://dx.doi.org/10.1002/adsc.201\#.

\begin{abstract}
A wide range of catalysts based on supported copper nanoparticles have been prepared and tested in the cross-dehydrogenative coupling of tertiary amines and terminal alkynes. Copper nanoparticles on zeolite $\mathrm{Y}$ has been found to be the most effective catalyst in the presence of tert-butyl hydroperoxide as the oxidant. Contrary to the previously reported methodologies involving copper catalysts, reactions have been accomplished without the need of an inert atmosphere and in the absence of solvent, using $1.5 \mathrm{~mol} \%$ catalyst. A variety of tertiary amines, including aromatic, benzylic and aliphatic ones, have been coupled with both aromatic and aliphatic alkynes to furnish the corresponding propargylamines in moderate-to-excellent yields.
\end{abstract}

The procedure has been successfully scaled-up to $12 \mathrm{mmol}$ with a high conversion (93\%). Moreover, the catalyst has been reused in seven cycles maintaining a good performance. Its catalytic activity has been compared with that of an array of commercial copper catalysts, being superior as regards the conversion and minimizing the alkyne homocoupling as a side reaction. The negative filtration test points to a process of heterogeneous nature. Based on compelling experimental evidence, a novel reaction mechanism has been delineated which outlines the essential role of free radicals and the couple copper(I)/copper(II).

Keywords: alkynes; amines; copper; crossdehydrogenative coupling; heterogeneous catalysis; nanoparticles; supported catalysts; zeolites.

\section{Introduction}

Propargylamines are a versatile class of compounds extensively applied as precursors in the synthesis of heterocyclic compounds such as quinolines, ${ }^{[1 \mathrm{a}]}$ phenanthrolines, ${ }^{[\mathrm{bb}]}$ pyrroles, ${ }^{[\mathrm{cc}]}{ }^{1 \mathrm{C}]}$ pyrrolidines, ${ }^{[\mathrm{ld}]}$ indolizines, ${ }^{[1 \mathrm{e}]}$ or oxazolidinones, ${ }^{[1 \mathrm{f}]}$ among others. ${ }^{[2]}$ They have also been utilized as intermediates in the total synthesis of some natural and pharmaceutical products. ${ }^{[3]}$ The propargylamine moiety can be found in a variety of bioactive compounds, ${ }^{[4]}$ some of which have been confirmed to be potent anti-apoptotic agents that protect neurons against cell death in cellular and animal models of neurodegenerative disorders. Indeed, they have been shown to delay the necessity for symptomatic therapy in untreated Parkinson's disease patients, results consistent with a neuroprotection role for compounds of this type. ${ }^{[5]}$ For instance, selegiline $\left(\right.$ Anipril ${ }^{\circledR}$ ) and rasagiline $\left(\right.$ Azilect ${ }^{\circledR}$ ) are current propargylamine-containing drugs for monotherapy in patients with early Parkinson's disease and for adjunctive therapy in patients with moderate to advanced disease. ${ }^{[5 c]}$ Pargyline (Eutonyl ${ }^{\circledR}$ ) is an irreversible inhibitor of monoamine oxidase (MAO) with antihypertensive
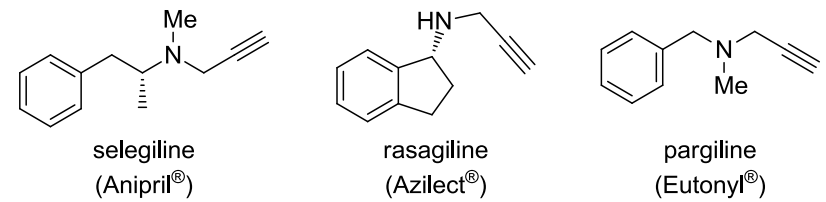

Figure 1. Some examples of bioactive propargylamines.

properties (Figure 1). ${ }^{[5 \mathrm{~d}]}$

Conventional methods for the formation of the propargylamine moiety include the direct amination of propargyl halides, ${ }^{[6]}$ triflates, ${ }^{[6 b]}$ phosphates, or acetates, ${ }^{[6]}$ or the more widely practiced addition of alkynylmetal reagents to imines [Scheme 1, eq. (1) and (2)]. ${ }^{[7]}$ The latter approach, normally involving stoichiometric amounts of lithium or magnesium acetylides, requires strict control of the reaction conditions and its application is precluded in the presence of reactive functional groups. More interesting is the metal-catalyzed multicomponent coupling of aldehydes, amines, and alkynes $\left(\mathrm{A}^{3}\right.$ coupling $)^{[8]}$ or the nucleophilic substitution of in-situ generated chloromethyl amines catalyzed by copper or silver [Scheme 1, eq. (3) and (4), respectively]. 


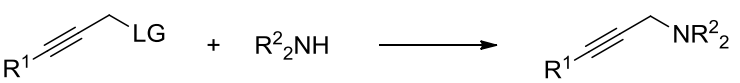

$L G=$ Hal, OTf, OP(O)OR ${ }_{2}^{3}, \mathrm{OAc}$, etc.

$$
\underset{\mathrm{M}=\mathrm{Li}, \mathrm{MgHal} \text {, etc. }}{\stackrel{\mathrm{R}}{\mathrm{R}_{1}^{1}}}
$$

Scheme 1. Some general methods for the synthesis of propargylamines.

In recent years, the catalytic cross-dehydrogenative coupling (CDC) has emerged as a powerful tool in organic synthesis which enables the construction of carbon-carbon bonds in an atom-economic and efficient manner [Scheme 1, eq. (5)]. ${ }^{[10]}$ In particular, the effective synthesis of propargylamines by CDC of terminal alkynes and tertiary amines, pioneered by $\mathrm{Li}$ et al. $^{[11]}$ has been accomplished under copper, ${ }^{[1,12]}$

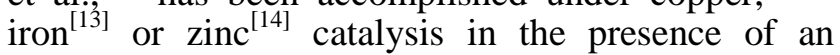
oxidant. Photoredox catalysis with ruthenium complexes is an alternative CDC path when the synthesis of propargylamines derived from tetrahydroisoquinolines is pursued. ${ }^{[15]}$ However, all the aforementioned methodologies are based on homogeneous catalysis, making the recovery and reutilization of the catalyst troublesome. During the development of the present work, ${ }^{[16]}$ reusable copper ferrite and metal-organic framework catalysts have been published for the CDC of terminal alkynes and tertiary amines. ${ }^{[17]}$ Another common feature for the reported methods is the limited substrate scope covered, as well as the presence of an inert atmosphere, generally a requirement under copper catalysis. $^{[11,12]}$

In the last decade, nano-catalysis has been established as a sustainable and competitive alternative to conventional catalysis since the metal nanoparticles possess a high surface-to-volume ratio, which enhances their activity and selectivity, while at the same time maintaining the intrinsic features of a heterogeneous catalyst. ${ }^{[18]}$ Owing to our increasing interest in metal colloids, ${ }^{[19]}$ we have developed some supported copper catalysts with diverse applications in organic synthesis. ${ }^{[20]}$ We wish to present herein a full study on the CDC access to propargylamines, by means of reusable supported copper nanoparticles, without the requisite of an inert atmosphere and under solvent-free conditions; our efforts to clarify the reaction mechanism are also included.

\section{Results and Discussion}

Initially, a variety of supported copper catalysts was prepared by addition of the support to a suspension of the freshly prepared copper nanoparticles (CuNPs), with the latter being readily generated from copper(II) chloride, lithium metal and a catalytic amount of DTBB (10 mol\%) in THF at room temperature. ${ }^{[21]}$ The as-prepared catalysts were tested in the CDC of $N, N$-dimethylaniline (1a) and phenylacetylene (2a) as model substrates, using $t$ BuOOH-decane as oxidizing agent ${ }^{[22]}$ (Table 1). A control experiment in the absence of catalyst led to the unchanged starting materials (entry 1 ). Solvent optimization with activated carbon as support ${ }^{[20 \mathrm{c}, 20 \mathrm{~d}]}$ (entries 2-10) allowed to conclude that the absence of solvent and presence of an inert atmosphere had a beneficial effect on the conversion (entry 10). Other inorganic supports such as $\mathrm{TiO}_{2}$, montmorillonite $\mathrm{K}$ 10 and zeolite $\mathrm{Y}$ exhibited better performance in comparison with activated carbon or $\mathrm{MgO}$, either in the presence or absence of an inert atmosphere

\begin{tabular}{|c|c|c|c|}
\hline Entry & $\begin{array}{l}\text { Support } \\
{[\mathrm{wt} \% \mathrm{Cu}]}\end{array}$ & $\begin{array}{l}\text { Solvent/ } \\
\text { atmosphere }\end{array}$ & $\begin{array}{l}\text { Conversion } \\
{[\%]^{[b]}}\end{array}$ \\
\hline 1 & no catalyst & none & 0 \\
\hline 2 & act. carbon $^{[\mathrm{c}]}[1.4]$ & $\mathrm{MeCN}$ & 23 \\
\hline 3 & act. carbon $[1.4]$ & $\mathrm{CH}_{2} \mathrm{Cl}_{2}$ & 0 \\
\hline 4 & act. carbon [1.4] & $\mathrm{MeOH}$ & 0 \\
\hline 5 & act. carbon [1.4] & $\mathrm{H}_{2} \mathrm{O}$ & 0 \\
\hline 6 & act. carbon [1.4] & $i$-PrOH & 16 \\
\hline 7 & act. carbon [1.4] & $\mathrm{PhMe}$ & 0 \\
\hline 8 & act. carbon [1.4] & THF & 0 \\
\hline 9 & act. carbon [1.4] & none & 24 \\
\hline 10 & act. carbon [1.4] & none/Ar & 33 \\
\hline 11 & $\mathrm{TiO}_{2}[3.0]$ & none & 63 \\
\hline 12 & $\mathrm{TiO}_{2}[3.0]$ & none/Ar & 53 \\
\hline 13 & mont $\mathrm{K}-10^{[\mathrm{d}]}[1.8]$ & none & 62 \\
\hline 14 & mont K-10 [1.8] & none/Ar & 67 \\
\hline 15 & $\mathrm{MgO}[1.5]$ & none & 43 \\
\hline 16 & $\mathrm{MgO}[1.5]$ & none/Ar & 9 \\
\hline 17 & zeolite Y [3.0] & none & 62 \\
\hline 18 & zeolite Y [3.0] & none/Ar & 67 \\
\hline 19 & $\mathrm{TiO}_{2}[3.0]^{[\mathrm{e}]}$ & none/Ar & $88(0)^{[\mathrm{f}]}$ \\
\hline 20 & mont $\mathrm{K}-10[1.8]^{[\mathrm{e}]}$ & none/Ar & $\begin{array}{l}92(63)^{[\mathrm{f}]} \\
(0)^{[\mathrm{g}]}\end{array}$ \\
\hline 21 & zeolite $\mathbf{Y}[3.0]^{[\mathrm{e}]}$ & none/Ar & $\begin{array}{l}\mathbf{8 9}(91)^{[\mathrm{f}]} \\
(93)^{[\mathrm{g}]}\end{array}$ \\
\hline 22 & zeolite Y [0] & none/Ar & 0 \\
\hline
\end{tabular}
(entries 11-18). The conversion attained with these three catalysts could be notably improved by using a

Table 1. Optimization of the type of support. ${ }^{[\mathrm{a}]}$

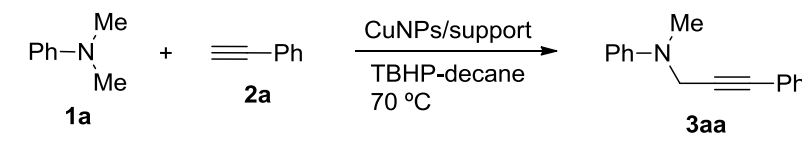

[a] 1a (0.5 mmol), $2 \mathbf{a}(0.5 \mathrm{mmol})$, CuNPs/support $(20 \mathrm{mg})$, $t$-BuOOH-decane (1.0 equiv.), solvent $(1 \mathrm{~mL}), 70^{\circ} \mathrm{C}, 24 \mathrm{~h}$. [b] Activated carbon. [c] Montmorillonite K-10. [d] Conversion determined by GLC. ${ }^{[\mathrm{e}]} \mathbf{1 a}(1.0 \mathrm{mmol}), \mathbf{2 a}(1.2$ $\mathrm{mmol}), \quad \mathrm{CuNPs} /$ support $(50 \mathrm{mg}), t$-BuOOH$-\mathrm{H}_{2} \mathrm{O} \quad(1.2$ equiv.), $70{ }^{\circ} \mathrm{C}, 24$ h. ${ }^{[\mathrm{f}]}$ Second cycle. ${ }^{[\mathrm{g}]}$ Third cycle. 
slight excess of the alkyne and $t-\mathrm{BuOOH}-\mathrm{H}_{2} \mathrm{O}$ as the oxidant under an argon atmosphere (entries 19-21). However, only $\mathrm{Cu}$ on zeolite $\mathrm{Y}$ could be effectively reused (entries 19-21, footnotes d and e). A control experiment with zeolite $\mathrm{Y}$ (without $\mathrm{Cu}$ ) demonstrated the inertness of this support towards the title reaction (entry 22).

Parallel to the above experiments with zeolite $\mathrm{Y}$ (ZY) and TBHP-decane, we studied any possible effect of the method of preparation of the catalyst on the outcome of the CDC reaction (Table 2). Three methods were implemented: impregnation (A), reduction-supporting $(\mathrm{B}$, the general method in Table 1) and impregnation-reduction $(\mathrm{C})$, with or without prior thermal treatment. In general, the presence of water, either in the original zeolite or in the impregnation step, favored the incorporation of copper (Table 2, compare entries 1 and 2 with 3 , and 6 with 7). In spite of the fact that method A provided higher conversions, only catalysts prepared by method B could be reused.

Table 2. Optimization of the method for catalyst preparation. ${ }^{[\mathrm{a}]}$

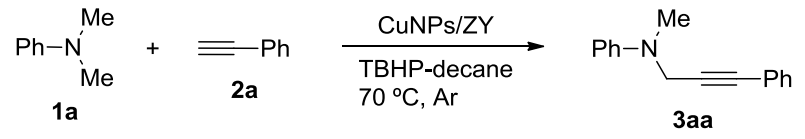

\begin{tabular}{|c|c|c|c|}
\hline Entry & Method $^{[b]}$ & {$[\mathrm{wt} \% \mathrm{Cu}]$} & $\begin{array}{l}\text { Conversion } \\
{[\%]^{[\mathrm{c}]}}\end{array}$ \\
\hline 1 & A-THF/Ar & 1.0 & 86 \\
\hline 2 & A-THF/Ar ${ }^{[\mathrm{d}]}$ & 2.1 & 77 \\
\hline 3 & A- $\mathrm{H}_{2} \mathrm{O} /$ air & 4.4 & 65 \\
\hline 4 & B-THF/Ar & 3.8 & 69 \\
\hline 5 & B-THF/Ar ${ }^{[\mathrm{d}]}$ & 3.7 & 56 \\
\hline 6 & C-THF/Ar ${ }^{[\mathrm{d}]}$ & 1.7 & 53 \\
\hline 7 & C- $\mathrm{H}_{2} \mathrm{O} /$ air & 3.6 & 48 \\
\hline
\end{tabular}

$t$-BuOOH-decane $\left(1.2\right.$ equiv.), $70{ }^{\circ} \mathrm{C}, 20 \mathrm{~h}, \mathrm{Ar}$. ${ }^{[\mathrm{b}]}$ Method of preparation of the catalyst: A, impregnation; $\mathbf{B}$, reduction-supporting; $\mathbf{C}$, impregnation-reduction; [c] Conversion determined by GLC. ${ }^{[d]} \mathrm{ZY}$ was previously dried at $100{ }^{\circ} \mathrm{C}$ for $0.5 \mathrm{~h}$.

Finally, the possibility of performing the CDC without the need of an inert atmosphere was explored by varying the amount of catalyst, and type and amount of TBHP (Table 3). The reactions in TBHPdecane (1.2 equiv.) under Ar showed an interesting trend: the conversion increased when decreasing the amount of catalyst (Table 3, entries 1-4), whereas a larger amount of the oxidant did not exert any significant improvement, either under $\mathrm{Ar}$ or air (Table 3, entries 5-7). Careful analysis of the data in table 3 allows to conclude that there is a minimum influence in the conversion of both the TBHP solvent and the atmosphere (compare entries 2, 3, and 11 with 9,8 and 13, respectively). High-to-quantitative conversions were reached when using 2 equiv. of the oxidant (Table 3, entries, 11 and 13-15), even at a
Table 3. Optimization of the conditions. ${ }^{[a]}$

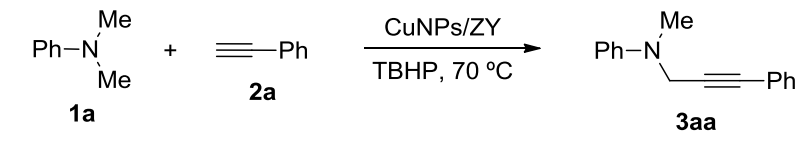

\begin{tabular}{|c|c|c|c|c|}
\hline Entry & Atmosphere & $\begin{array}{l}\text { Catalyst } \\
{[\mathrm{mg}]^{[b]}}\end{array}$ & $\begin{array}{l}\text { TBHP } \\
\text { [equiv.] }^{[c]}\end{array}$ & $\begin{array}{l}\text { Conv. } \\
{[\%]^{[\mathrm{d}]}}\end{array}$ \\
\hline 1 & $\mathrm{Ar}$ & 100 & decane (1.2) & 38 \\
\hline 2 & $\mathrm{Ar}$ & 50 & decane (1.2) & 69 \\
\hline 3 & $\mathrm{Ar}$ & 25 & decane (1.2) & 80 \\
\hline 4 & $\mathrm{Ar}$ & 12.5 & decane (1.2) & 83 \\
\hline 5 & $\mathrm{Ar}$ & 50 & decane (2.0) & 76 \\
\hline 6 & air & 50 & decane (1.2) & 67 \\
\hline 7 & air & 50 & decane (2.0) & 77 \\
\hline 8 & $\mathrm{Ar}$ & 25 & $\mathrm{H}_{2} \mathrm{O}(1.2)$ & 76 \\
\hline 9 & $\mathrm{Ar}$ & 50 & $\mathrm{H}_{2} \mathrm{O}(1.2)$ & 73 \\
\hline 10 & $\mathrm{Ar}$ & 50 & $\mathrm{H}_{2} \mathrm{O}(1.5)$ & 82 \\
\hline 11 & Ar & 50 & $\mathrm{H}_{2} \mathrm{O}(2.0)$ & $>99$ \\
\hline 12 & air & 50 & $\mathrm{H}_{2} \mathrm{O}(1.2)$ & 84 \\
\hline 13 & air & 50 & $\mathrm{H}_{2} \mathrm{O}(\mathbf{2 . 0})$ & $>99$ \\
\hline 14 & air & 25 & $\mathrm{H}_{2} \mathrm{O}(2.0)$ & 91 \\
\hline 15 & air & 12.5 & $\mathrm{H}_{2} \mathrm{O}(2.0)$ & 90 \\
\hline
\end{tabular}

$70^{\circ} \mathrm{C}, 20 \mathrm{hmol}$ ), 2a (1.2 mmol), CuNPs/ZY, $t$-BuOOH,

${ }^{[c]} 6 \mathrm{M}$ in decane or $80 \%$ in $\mathrm{H}_{2} \mathrm{O} .{ }^{[\mathrm{d}]}$ Conversion determined by GLC.

lower catalyst loading (entry 15, 0.38 mol\%). Therefore, the conditions in entry 13 were considered the optimum for the substrate scope study (see below).

The copper-on-zeolite $\mathrm{Y}$ catalyst prepared by the method B was characterized by different means. The copper content in the catalysts, $c a$. 3.0-3.8 wt $\%$, was determined by inductively coupled plasma optical emission spectroscopy (ICP-OES). Analysis by TEM revealed the presence of spherical monodisperse nanoparticles $(\sigma=0.347)$ unevenly distributed on the zeolite surface with diameters of $c a .1 .7 \pm 0.7 \mathrm{~nm}$ (Figure 2). Energy-dispersive X-ray (EDX) analysis on various regions confirmed the presence of copper, ${ }^{[20 a]}$ with energy bands of $8.04,8.90 \mathrm{keV}$ (K lines) and $0.92 \mathrm{keV}$ (L line) (Figure 3). X-ray diffraction (XRD) and selected area electron diffraction (SAED) analyses mainly showed signals corresponding to zeolite Y (Supporting information). ${ }^{[23 a]}$ XPS analysis showed four $\mathrm{Cu}\left(2 p_{3 / 2}\right)$ peaks at 932.6, 934.6, 941.5 and $944.1 \mathrm{eV}$. These peaks could be assigned to $\mathrm{Cu}_{2} \mathrm{O}(932.6 \mathrm{eV})$ and $\mathrm{CuO}$ $(934.6 \mathrm{eV})$, with the peaks at 941.5 and $944.1 \mathrm{eV}$ being the satellite shakeup features characteristic of $\mathrm{Cu}^{2+}$ species (Figure 4). ${ }^{[23 \mathrm{~b}, 23 \mathrm{cc}]}$

With the optimized catalyst and conditions in hand, we next studied the substrate scope (Table 4). First, $\mathrm{N}, \mathrm{N}$-dimethylaniline was combined with aromatic alkynes bearing either electron-donating or withdrawing groups to give the corresponding products 3aa-3ad in good-to-excellent yields (Table 

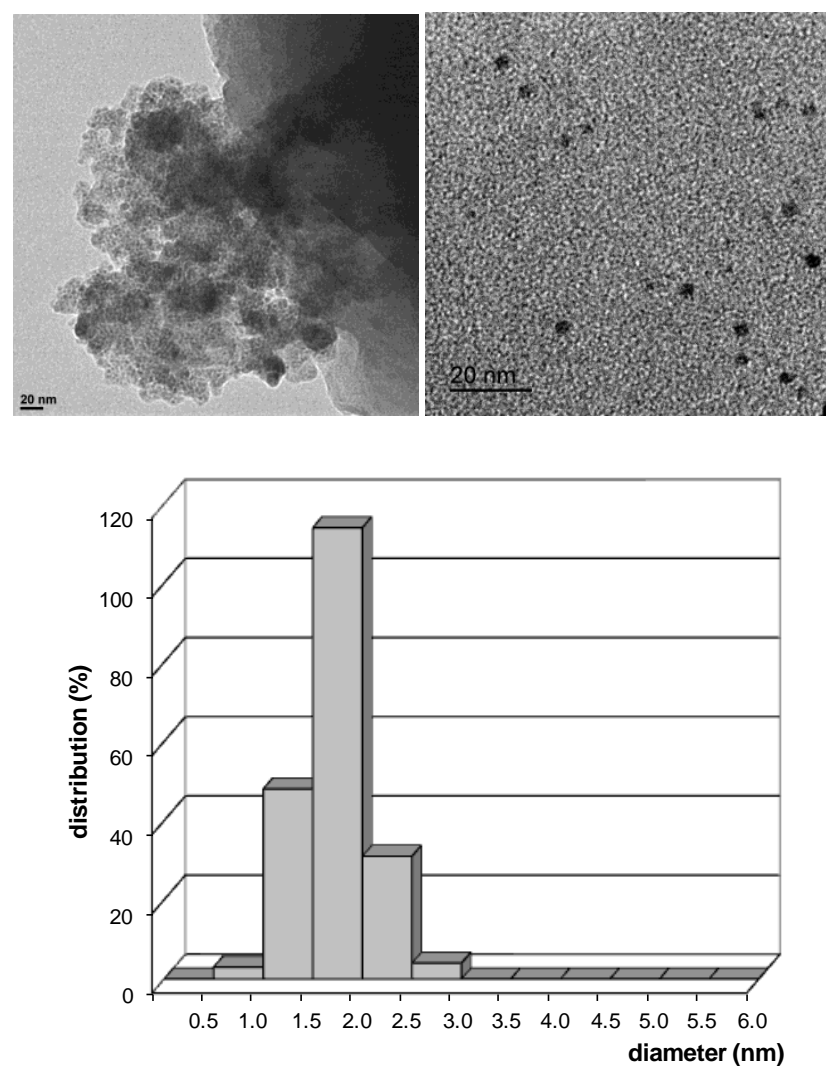

Figure 2. TEM micrograph and particle size distribution of CuNPs/ZY. The sizes were determined for 200 nanoparticles selected at random.

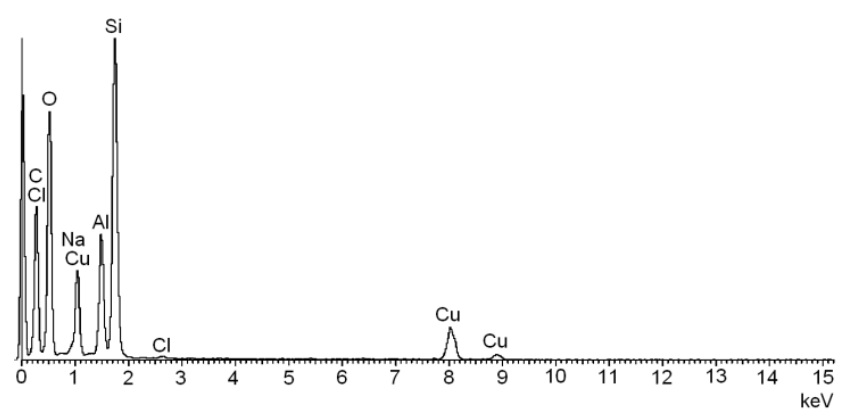

Figure 3. EDX spectrum of CuNPs/ZY.

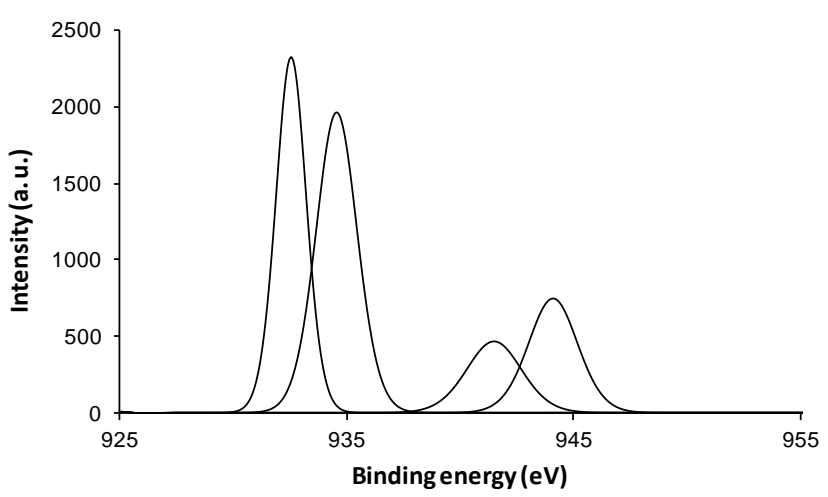

Figure 4. XPS spectrum of CuNPs/ZY at the $\mathrm{Cu} 2 p_{3 / 2}$ level.
4, entries 1-4). The method was equally effective for aliphatic alkynes, including alkyl-chain, cyclic and functionalized alkynes (Table 4, entries 5-9). It is noteworthy that the reaction conditions were compatible with the presence of chloro, ester and alcohol functionalities (Table 4, entries 7-9). Then, the electronic character of the starting aniline was changed; electron-donating groups at the para position favored the CDC to furnish the propargyl amines 3ba and 3ca in high yields (Table 4, entries 10 and 11). In contrast, $N, N$-dimethylanilines with electron-withdrawing groups at the para position reacted sluggishly, even at $100{ }^{\circ} \mathrm{C}$, affording the expected products 3da and 3ea in modest yields (Table 4, entries 12 and 13). This result is not so unexpected if we consider that electron-withdrawing groups at the para position can destabilize the intermediate iminium species.

Concerning benzylamines, the coupling of the $N, N$ dimethyl derivatives was highly regioselective, taking place at the methyl group instead of at the benzylic position, in moderate yields (Table 4, entries 14 and 15). 2-Phenyl-1,2,3,4-tetrahydroisoquinoline gave the expected product 3ha in moderate yield (Table 4, entry 16). Finally, we must point out that the same catalytic system was successfully applied to the CDC of aliphatic amines and alkynes; aliphatic amines are very rarely studied substrates ${ }^{[14]}$ and, in general, copper catalysis in the presence of an oxidant leads to poor yields of the CDC products. ${ }^{[12 a]} \mathrm{We}$ were delighted to check that the CDC of both $N, N$ dimethylcyclohexylamine (1i) and tropinone $(\mathbf{1 j})$ with phenylacetylene (2a) provided the propargylamines 3ia and 3ja in excellent and modest yields, by exclusive reaction at the methyl group (Table 4, entries 17 and 18).

Interestingly, the CDC of the secondary amine $\mathrm{N}$ methylaniline (1k) with phenylacetylene (2a) produced quantitatively the same propargylamine 3aa as that derived from 1a (Scheme 2). This methylation-alkynylation process has been recently described by Phan and Truong et al. using copper ferrite $\left(5 \% \mathrm{CuFe}_{2} \mathrm{O}_{4}, \mathrm{DMA}, 140{ }^{\circ} \mathrm{C}\right)^{[24 \mathrm{a}]}$ and a copper MOF (5\% catalyst, DMA, $\left.120^{\circ} \mathrm{C}\right)^{[24 \mathrm{~b}]}$ in the presence of TBHP (3 equiv.) as the oxidant under argon.

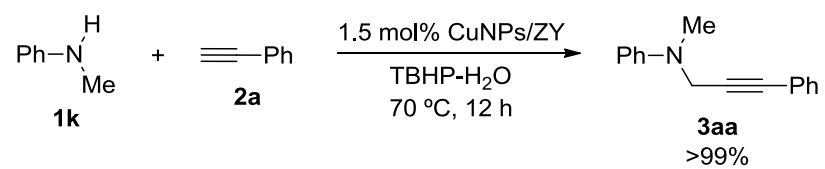

Scheme 2. CDC of $\mathbf{1 1}$ and $\mathbf{2 a}$ catalyzed by CuNPs/ZY

Under the same conditions as above but using TMEDA (11) as the tertiary amine, a mixture of monoalkynylated $\mathbf{1 l}$ (3la) and aminomethylated 2a (4) was obtained. This result is in agreement with the observations of Li et al., ${ }^{[25]}$ namely: TBHP favored the formation of $\mathbf{4}$ versus 3la, contrary to what observed with molecular oxygen (Scheme 3 ). 
Table 4. CDC of tertiary amines and terminal alkynes catalyzed by CuNPs/ZY. ${ }^{[a]}$

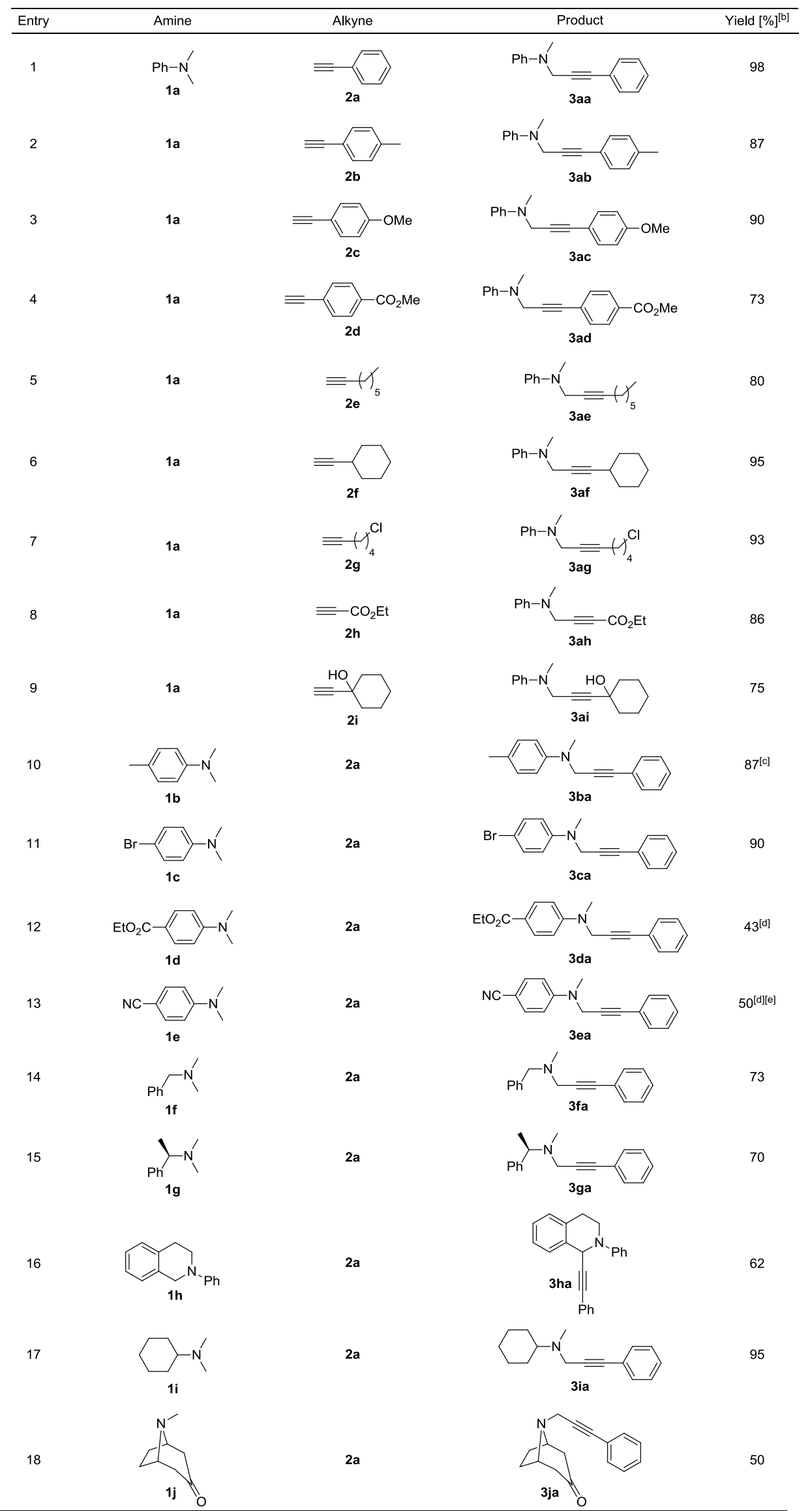

[a] $1(1.0 \mathrm{mmol}), 2$ (1.2 mmol), CuNPs/ZY (1.5 mol\%), $t$-BuOOH-H $\mathrm{O}$ (2.0 equiv.), $70{ }^{\circ} \mathrm{C}, 15-20 \mathrm{~h} .{ }^{\text {[b] }}$ Isolated yield. $^{\text {[c] }}$ Yield after distillation. ${ }^{[\mathrm{d}]}$ Reaction at $100{ }^{\circ} \mathrm{C}$. ${ }^{[\mathrm{e}]} \mathrm{NMR}$ yield. 


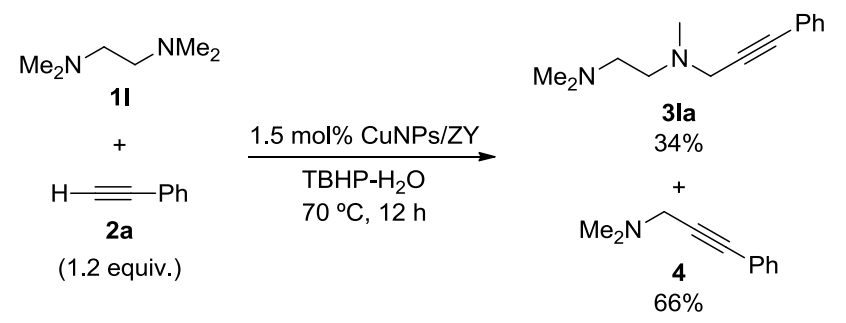

Scheme 3. CDC of $\mathbf{1 l}$ and 2a catalyzed by CuNPs/ZY.

It is worthwhile mentioning that all the CDC reactions were carried out without air exclusion. In addition, the catalyst could be easily recovered by centrifugation and reutilized, leading to propargylamine 3aa in high yield over seven consecutive cycles (Figure 5). Furthermore, the standard procedure was successfully scaled-up to 12 $\mathrm{mmol}$, giving rise to the product in $93 \%$ conversion at $1.5 \mathrm{~mol} \%$ catalyst loading and $67 \%$ at $0.38 \mathrm{~mol} \%$. The kinetic profile for the CDC of 1a and 2a at 12 mmol scale shows an induction period of $c a .1 \mathrm{~h}$ (Figure 6).

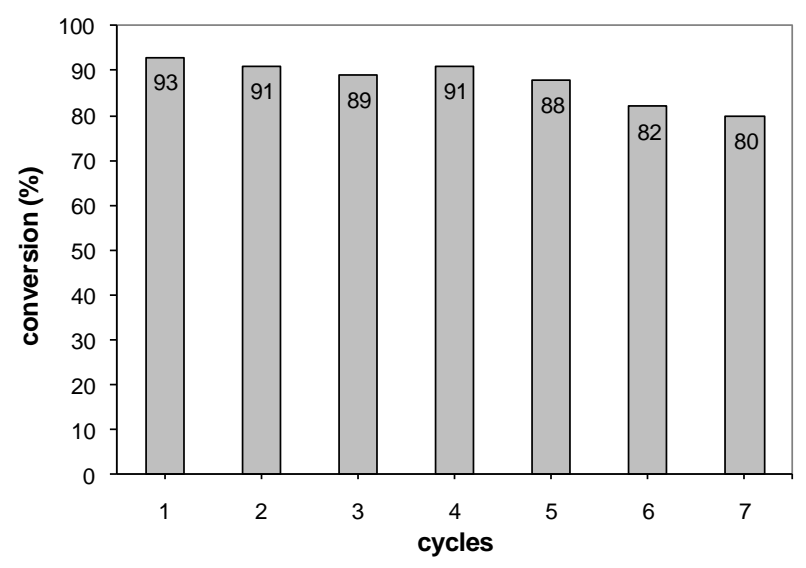

Figure 5. Recycling of CuNPs/ZY in the synthesis of 3aa.

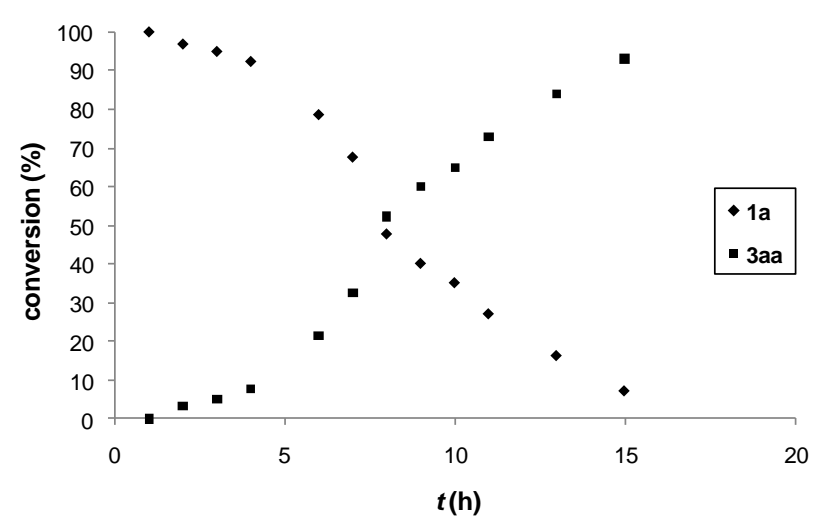

Figure 6. Plot showing the evolution of the CDC of $\mathbf{1 a}$ and 2a at $12 \mathrm{mmol}$ scale (standard conditions, $1.5 \mathrm{~mol} \%$ CuNPs/ZY).
In order to unveil the nature of the catalysis, the standard reaction of 1a and 2a was run up to a 5\% conversion. Then, the catalyst was filtered and the resulting filtrate was subjected to additional heating at $70{ }^{\circ} \mathrm{C}$ for $12 \mathrm{~h}$; the original conversion remained constant $(5 \%)$. The negligible amount of copper $(0.78$ $\mathrm{ppb}$ ) detected by ICP-MS analysis of a filtrate sample, confirmed the absence of leaching and points to a process of heterogeneous nature. The likelihood of the catalyst acting as a reservoir for metal species that leach into solution and readsorb cannot be fully rejected. ${ }^{[26]}$ However, recently, Scaiano et al. combined standard bench scale techniques with single-molecule spectroscopy to monitor the CuNPcatalyzed azide-alkyne cycloaddition (which also involves copper acetylides) and prove that catalysis occurs at the surface of the CuNPs. ${ }^{[27]}$

We next compared the CuNPs/ZY catalyst with some commercially available copper catalysts in the standard reaction of $N, N$-dimethylaniline (1a) and phenylacetylene (2a) at $1-10 \mathrm{~mol} \%$ catalyst loading. (Table 5 and Figure 7). $\mathrm{CuCl}(10 \mathrm{~mol} \%), \mathrm{CuBr}(10$ mol\%) and $\mathrm{CuBr} \cdot \mathrm{SMe}_{2}(2 \mathrm{~mol} \%)$ gave the highest conversions into 3aa (Table 5, entries 4, 6 and 14). All the other commercial catalysts led to substantial amounts of the by-product 1,4-diphenylbuta-1,3diyne (5a), resulting from the alkyne homocoupling. ${ }^{[28]}$ The CuNPs/ZY catalyst was found to be distinctly superior, reaching the highest conversion without producing the undesired diyne (Table 5, entry 16). Therefore, the nanosized character of the catalyst seems to be fundamental.

Table 5. CDC of $\mathbf{1 a}$ and $\mathbf{2 a}$ catalyzed by commercial $\mathrm{Cu}$ catalysts. $^{\text {[a] }}$

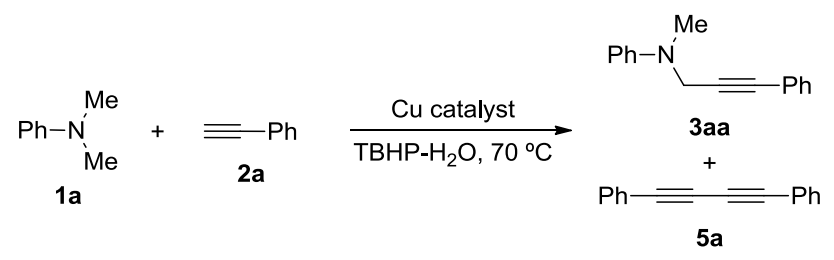

\begin{tabular}{llll}
\hline Entry & Catalyst & mol[\%] & $\mathbf{1 a / 3 a a} / \mathbf{5 a}[\%]^{[\mathrm{b}]}$ \\
\hline 1 & $\mathrm{Cu}(0)$ & 10 & $37 / 50 / 13$ \\
2 & $\mathrm{Cu}{ }_{2} \mathrm{O}$ & 10 & $22 / 53 / 25$ \\
3 & $\mathrm{CuO}$ & 10 & $93 / 5 / 2$ \\
4 & $\mathrm{CuCl}$ & 10 & $11 / 74 / 15$ \\
5 & $\mathrm{CuCl}{ }_{2}$ & 10 & $11 / 39 / 50$ \\
6 & $\mathrm{CuBr}$ & 10 & $14 / 79 / 7$ \\
7 & $\mathrm{CuI}$ & 10 & $12 / 68 / 20$ \\
8 & $\mathrm{Cu}(\mathrm{OAc})_{2}$ & 10 & $26 / 61 / 13$ \\
9 & $\mathrm{CuBr} \cdot \mathrm{SMe}_{2}$ & 10 & $27 / 67 / 6$ \\
10 & $\mathrm{Cu}(\mathrm{OTf})_{2}$ & 10 & $44 / 40 / 16$ \\
11 & $\mathrm{CuBr}$ & 1 & $50 / 42 / 8$ \\
12 & $\mathrm{CuI}$ & 1 & $24 / 62 / 14$ \\
13 & $\mathrm{Cu}(\mathrm{OAc})_{2}$ & 2 & $17 / 59 / 24$ \\
14 & $\mathrm{CuBr} \cdot \mathrm{SMe}{ }_{2}$ & 2 & $20 / 75 / 5$ \\
15 & $\mathrm{Cu}(\mathrm{OTf})_{2}$ & 2 & $24 / 56 / 20$ \\
$\mathbf{1 6}$ & $\mathbf{C u N P s} / \mathbf{Z Y}$ & $\mathbf{1 . 5}$ & $\mathbf{0} />\mathbf{9 9 / 0}$ \\
\hline
\end{tabular}

[a] 1a $(1.0 \mathrm{mmol}), \mathbf{2 a}(1.2 \mathrm{mmol}), \mathrm{Cu}$ catalyst, $t$-BuOOH$\mathrm{H}_{2} \mathrm{O}$ (2.0 equiv.), $70{ }^{\circ} \mathrm{C}, 24 \mathrm{~h}$, in air. ${ }^{[b]}$ The ratio was determined by GLC. 


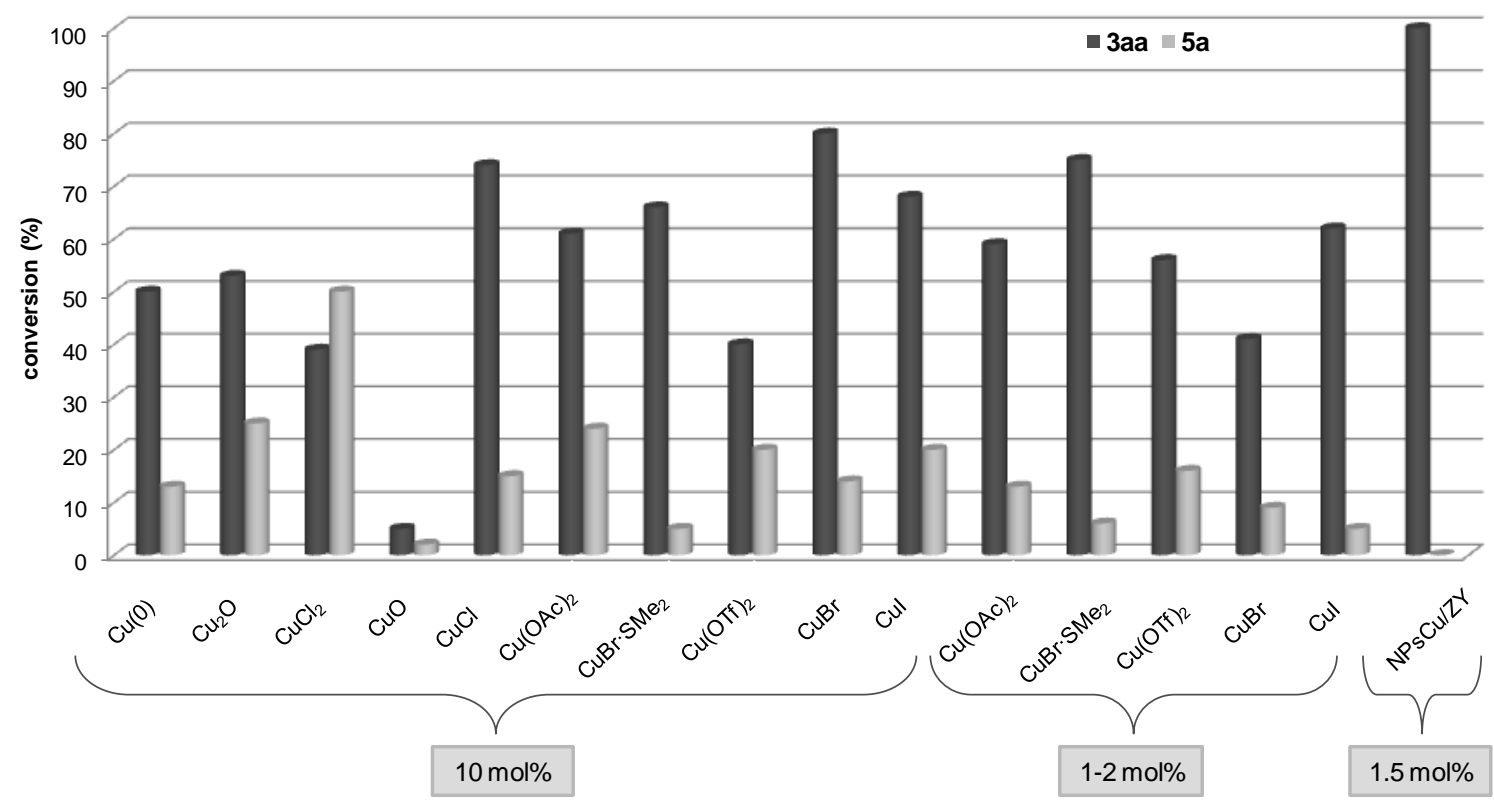

Figure 7. Graphic showing the CDC product (3aa)/alkyne homocoupling (5a) ratio in the reaction of 1a and 2a catalyzed by commercial $\mathrm{Cu}$ catalysts and CuNPs/ZY (see the conditions in Table 5).

Table 6. CDC of $\mathbf{1 a}$ and $\mathbf{2 a}$ in the presence of radical scavengers. ${ }^{[\mathrm{a}]}$

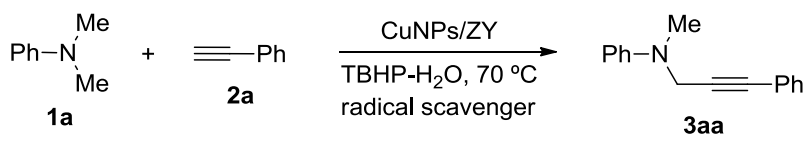

\begin{tabular}{lll}
\hline Entry & Radical scavenger & Conversion $[\%]^{[\mathrm{b}]}$ \\
\hline 1 & norbornene & 92 \\
2 & cumene & 80 \\
3 & 2,6-di-tert-butylphenol & $65^{[\mathrm{c}]}$ \\
4 & TEMPO $^{[\mathrm{d}]}$ & $10^{[\mathrm{e}]}$
\end{tabular}

[a] 1a $(1.0 \mathrm{mmol}), \mathbf{2 a}(1.2 \mathrm{mmol}), \mathrm{CuNPs} / \mathrm{ZY}(1.5 \mathrm{~mol} \%)$, $t$ - $\mathrm{BuOOH}-\mathrm{H}_{2} \mathrm{O}$ (2.0 equiv.), radical scavenger (1.0 equiv.), $70{ }^{\circ} \mathrm{C}, 20 \mathrm{~h}$, air. ${ }^{[\mathrm{b}]}$ Conversion determined by GLC. ${ }^{[\mathrm{c}]}$ 2,6Di-tert-butylanisole was formed in $c a .40 \%$ conversion. ${ }^{\text {[d] }}$ 2,2,6,6-Tetrametilpiperidin-1-oxil. [e] 1-Methoxy-2,2,6,6tetramethylpiperidine was formed in $c a .75 \%$ conversion.

There has been much debate around the mechanism of the CDC, particularly concerning the radical or ionic generation of the intermediate iminium ion. ${ }^{[11 \mathrm{~d}, 29]}$ A series of control experiments were conducted, including the use of radical scavengers, in order to gain an insight into the reaction mechanism (Table 6). Among the different radical traps tested, 2,6-di-tert-butylphenol and, more markedly, TEMPO inhibited considerably the CDC, with the concomitant formation of 2,6-di-tertbutylanisole (ca. 40\%) and 1-methoxy-2,2,6,6tetramethylpiperidine (ca. $75 \%$ ), respectively; i.e. the reaction products between those traps and methyl radical (Table 6, entries 3 and 4).

In principle, methyl radicals could be formed through a $\beta$-cleavage of TBHP, followed by a homolytic Me-CO bond cleavage, to eventually release acetone as a neutral molecule. We used 2,4dinitrophenylhydrazine (2,4-DNPH) as an acetone scavenger to detect its presence as the corresponding hydrazone. Certainly, the addition of 2,4-DNPH to a standard reaction elapsed $5 \mathrm{~h}$, led to the formation of a white precipitate which was identified as acetone 2,4-dinitrophenylhydrazone (6) (Scheme 4). Notwithstanding transition metals can catalyze the fragmentation of TBHP into tert-butoxyl radicals, ${ }^{[30]}$ two control experiments proved that $\beta$-cleavage in TBHP can take place at the CDC standard temperature in the absence of the copper catalyst (Scheme 5). Additional essays performed under solvent-less conditions for $5 \mathrm{~h}$ with different oxidants were really very enlightening (Scheme 6): (a) benzoyl peroxide, which decomposes into $\mathrm{PhCO}_{2}{ }^{\bullet}$ and $\mathrm{Ph}$ did not give 3aa at all; (b) di-tert-butyl peroxide, which is able to generate $t$ - $\mathrm{BuO}^{\bullet}$ and $\mathrm{Me}^{\bullet}$, formed

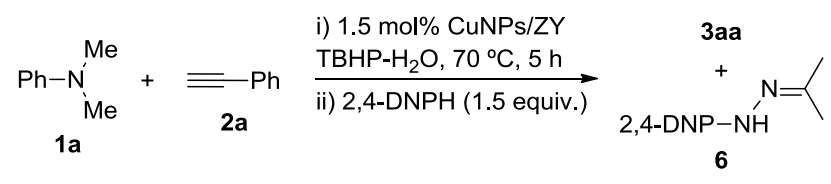

Scheme 4. Experiment demonstrating the generation of acetone in the CDC of $\mathbf{1 a}$ and $\mathbf{2 a}$.

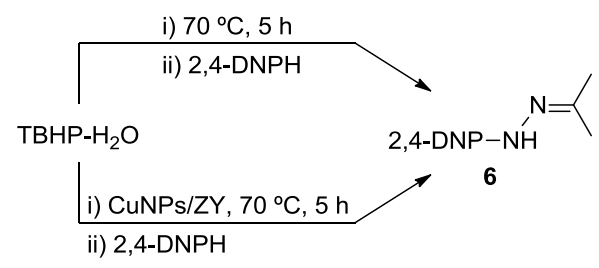

Scheme 5. Control experiments on the transformation of TBHP into acetone. 


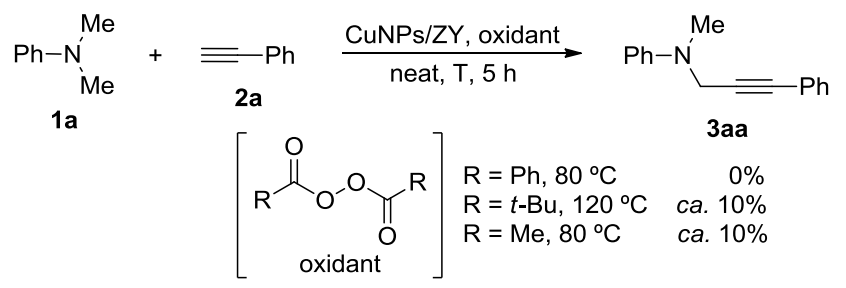

Scheme 6. CDC of 1a and 2a catalyzed by CuNPs/ZY in the presence of different peroxides.

3aa in ca. $10 \%$ conversion; (c) similar percentage was recorded with acetyl peroxide, which can split into $\mathrm{Me}^{\bullet}$. This conversion is within the expected range for a standard reaction after $5 \mathrm{~h}$ (Figure 6), albeit the reaction conditions are different: they were carried out at the decomposition temperature of the oxidant in the absence of water (Scheme 6). These results reinforce the hypothesis that highly reactive methyl radicals may play a key role in the $\mathrm{CDC}$ with TBHP as the oxidant.

The function of copper is also questionable, given that it can participate in the in-situ formation of the nucleophile but also in the oxidation of the substrate. The situation is especially intriguing when, as in our case, two oxidation states are present in the catalyst $[\mathrm{Cu}(\mathrm{I})$ and $\mathrm{Cu}(\mathrm{II})]$. We analyzed by XPS the recovered catalyst at the end of a typical reaction and, much to our surprise, the intensity of $\mathrm{Cu}$ (II) was extensively depleted (Figure 8a); the copper was mostly as $\mathrm{Cu}_{2} \mathrm{O}$, what could be additionally corroborated by the $\mathrm{CuL}_{3} \mathrm{M}_{45} \mathrm{M}_{45}$ Auger peak located at $571.0 \mathrm{eV}$ (Supporting information). ${ }^{\text {[31] }}$ Treatment
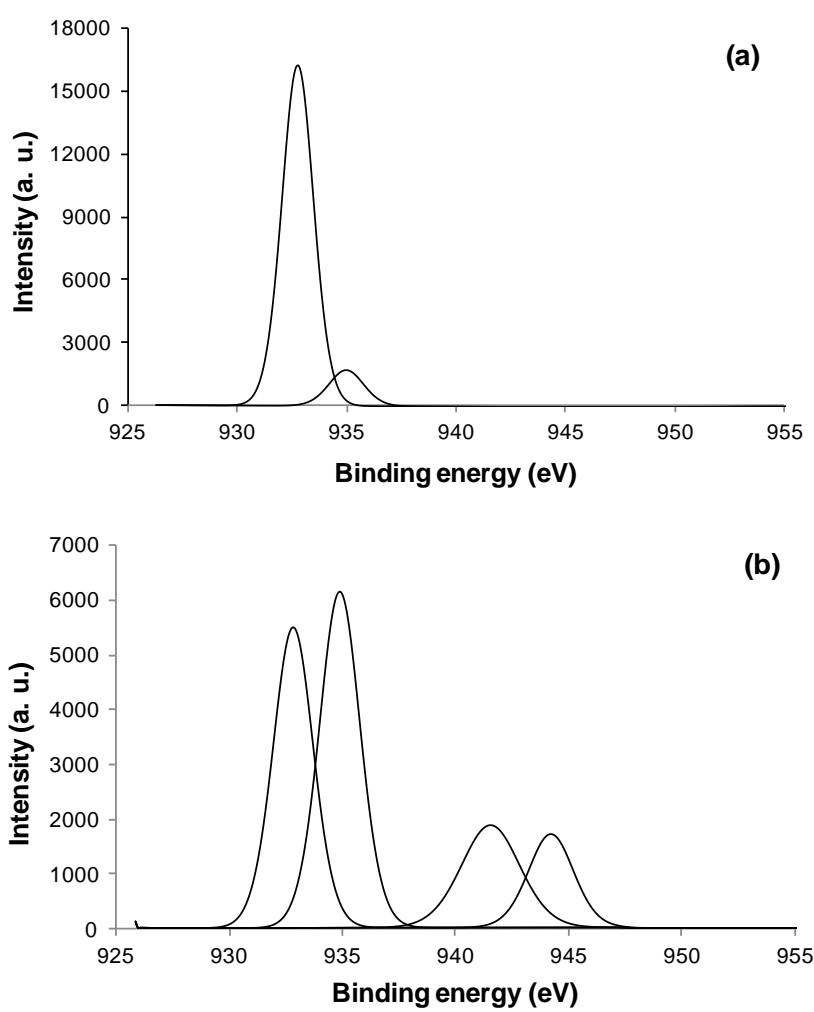

Figure 8. XPS spectrum of CuNPs/ZY at the $\mathrm{Cu} 2 p_{3 / 2}$ level (a) at the end of the CDC and (b) after reoxidation. of the same catalyst sample with $\mathrm{TBHP}-\mathrm{H}_{2} \mathrm{O}$ at $70^{\circ} \mathrm{C}$ for $5 \mathrm{~h}$ and subsequent analysis by XPS brought into view the regeneration of $\mathrm{Cu}$ (II) to get nearly the original $\mathrm{Cu}(\mathrm{I}) / \mathrm{Cu}$ (II) ratio (Figure $8 b$ ). This finding unmasks $\mathrm{Cu}$ (II) as a crucial player in the $\mathrm{CDC}$, despite the general trend that $\mathrm{Cu}(\mathrm{I})$ salts perform better than the $\mathrm{Cu}$ (II) counterparts when excess of oxidant is present. It is our belief that most of the success of the CDC with CuNPs resides on the conjunction of both $\mathrm{Cu}(\mathrm{I})$ and $\mathrm{Cu}(\mathrm{II})$ species and their redox activities.

Gathering and interpreting the above results, a tentative mechanism was proposed in which some of the following events could occur parallely (Scheme 7): (a) Alkyne activation by $\mathrm{Cu}_{2} \mathrm{ONPs}$ to form the corresponding copper acetylide; the formation of the latter was previously demonstrated by us ${ }^{[20 \mathrm{~b}]}$ and was found to be especially favored in aqueous medium. ${ }^{[32]}$ (b) Thermal-promoted $\beta$-cleavage of TBHP to give tert-butoxyl and hydroxyl radicals, with further evolution of the former into methyl radical and acetone. (c) Amine oxidation by CuONPs to give its derived radical cation and $\mathrm{Cu}_{2} \mathrm{ONPs}$; although some direct oxidation of the amine by TBHP cannot be ruled out, the marked decrease in intensity of $\mathrm{Cu}$ (II) in such an oxidative medium (Figure 8a) indicates its decisive part in this step. (d) Re-oxidation of $\mathrm{Cu}_{2} \mathrm{ONPs}$ to CuONPs by the action of TBHP (or the combined action of TBHP and $\mathrm{O}_{2}$ ) and the concomitant production of tert-butoxyl radical and hydroxyl anion. (e) Hydrogen-atom transfer (HAT) between the amine radical cation and the methyl radical giving rise to the iminium ion; the cooperation to some extend of other radicals in the HAT process cannot be fully discarded, although methyl radical seems to have a prominent participation. Whether the SET comes before the HAT or vice versa is difficult to ascertain, ${ }^{[33]}$ even though dimers of the putative radicals of 1a in the absence of the catalyst have not been detected, what would suggest a SET-HAT sequence. (f) The eventual addition of the copper acetylide to the iminium ion would afford the propargylamine.

As a final remark, we must underline that the CDC reported herein is highly regioselective; tertiary amines prone to activation in different $\mathrm{C}-\mathrm{H}$ bonds underwent alkynylation exclusively at the methyl group. Such is the case of the benzylic amines $\mathbf{1 f}$ and 1g, $N, N$-dimethylcyclohexylamine (1i) and tropinone (1j). Some stereoelectronic effects have been invoked to rationalize this selectivity, namely: the necessity of periplanarity of the partially occupied orbital on the nitrogen of the intermediate amine radical cation with the $\alpha \mathrm{C}-\mathrm{H}$ bond. ${ }^{[29,34]}$ Surely, this explanation can account for the selectivity attained in the case of tropinone (1j), but it is not so obvious in the other examples. Probably, in those cases, the HAT is merely driven by steric effects, involving the most accessible $\alpha \mathrm{C}-\mathrm{H}$ bond to the radical, to generate the terminal kinetic iminium ion rather than the internal thermodynamic one. 


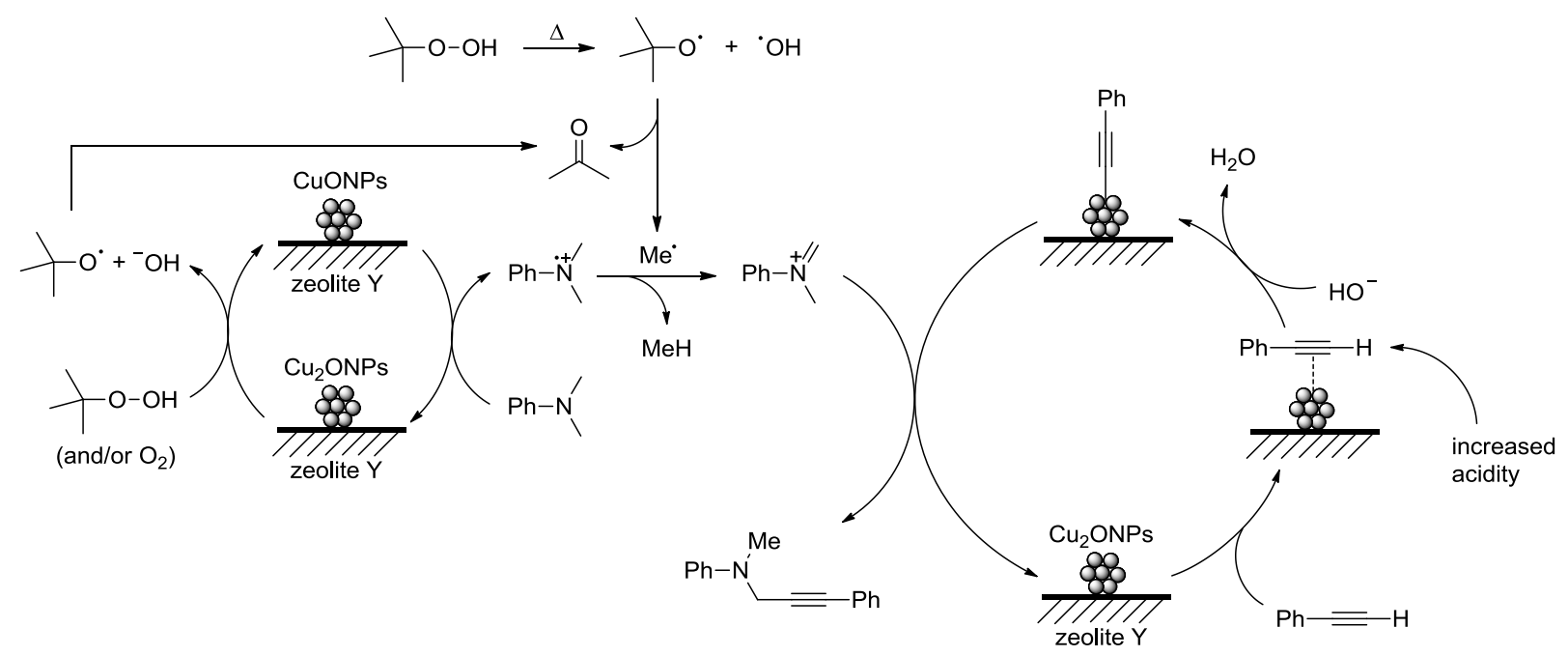

Scheme 7. Reaction mechanism proposed for the CDC of $N, N$-dimethylaniline and phenylacetylene catalyzed by CuNPs/ZY in the presence of TBHP.

\section{Conclusion}

In conclusion, we have presented a new heterogeneous catalyst for the CDC of tertiary amines and terminal alkynes comprised of oxidized copper nanoparticles on sodium Y zeolite, readily prepared from commercially available chemicals under mild conditions. The catalyst $(1.5 \mathrm{~mol} \%)$, in the presence of aqueous TBHP, has been applied to the formation of an array of propargylamines in moderate-toexcellent yields. Contrary to other previously reported methodologies, it has been demonstrated that the copper-catalyzed CDC can be conducted under solvent-free conditions and without the requirement of an inert atmosphere. The reaction conditions were compatible with the presence of different functionalities such as methoxy, ester, cyano, hydroxy, halogen and ketone. Not only activated $\mathrm{N}, \mathrm{N}$-dimethylanilines have been covered in this study but benzyl and aliphatic amines. The catalyst has been successfully both reutilized in seven successive runs and adapted to a $12 \mathrm{mmol}$ scale. Moreover, its catalytic activity surpasses that of various commercially available copper catalysts, depleting the formation of 1,3-diynes as by-products. We have endeavored to propose a reaction pathway which discloses the pivotal role of free radicals (methyl radical, in particular) and that of the $\mathrm{Cu}(\mathrm{I}) / \mathrm{Cu}$ (II) redox couple. The results of this study also highlight the utility of nanosized copper in catalysis when compared with bulk copper sources.

\section{Experimental Section}

Anhydrous copper(II) chloride (97\%, Aldrich), lithium powder from granulated lithium (Chemetall), DTBB $\left(4,4^{\prime}\right.$ di-tert-butylbiphenyl, Aldrich), TBHP (5-6 M in decane or $70 \mathrm{wt} . \%$ in water, Aldrich) and sodium Y zeolite (Aldrich) were commercially available. $N, N$-Dimethylaniline (Carlo Erba) was distilled before use. All other starting materials and reagents were commercially available of the best grade (Aldrich, Acros, Alfa Aesar) and were used without further purification. THF was dried in a Sharlab PS-400-3MD solvent purification system using an alumina column. All reactions were carried out on a multireactor apparatus using the corresponding reactor tubes. Melting points were obtained with a Reichert Thermovar apparatus and are uncorrected. Optical rotations were measured using a Perkin-Elmer 341 polarimeter with a thermally jacketted 5 $\mathrm{cm}$ cell at approximately $20{ }^{\circ} \mathrm{C}$. Concentrations $(c)$ are given in $\mathrm{g} / 100 \mathrm{ml}$ and $[\alpha]$ values are given in units of $10^{-1}$ $\operatorname{deg} \mathrm{cm}^{2} \mathrm{~g}^{-1}$. NMR spectra were recorded on Bruker Avance 300 and 400 spectrometers $(300$ and $400 \mathrm{MHz}$ for ${ }^{1}$ H NMR; 75 and $101 \mathrm{MHz}$ for ${ }^{13} \mathrm{C}$ NMR); chemical shifts are given in $(\delta)$ parts per million and coupling constants $(J)$ in Hertz. Infrared analysis was performed with a Jasco 4100LE (Pike MIRacle ATR) spectrophotometer; wavenumbers $(\tilde{v})$ are given in $\mathrm{cm}^{-1}$. Mass spectra (EI) were obtained at $70 \mathrm{eV}$ on an Agilent 5973 spectrometer; fragment ions in $\mathrm{m} / \mathrm{z}$ with relative intensities $(\%)$ in parentheses. HRMS analyses were also carried out in the electron impact mode (EI) at $70 \mathrm{eV}$ on a Finnigan MAT95S spectrometer. Elemental analyses were performed on a Leco Micro TruSpec CHNS microanalyzer. The purity of volatile compounds and the chromatographic analyses (GLC) were determined with an Agilent $6890 \mathrm{~N}$ instrument equipped with a flame ionization detector and an HP-5MS $30 \mathrm{~m}$ capillary column $(0.32 \mathrm{~mm}$ diameter, $0.25 \mu \mathrm{m}$ film thickness $)$, using nitrogen $(2 \mathrm{~mL} / \mathrm{min})$ as carrier gas, $T_{\text {injector }}=2700^{\circ} \mathrm{C}, T_{\text {column }}=60^{\circ} \mathrm{C}(3 \mathrm{~min})$ and $60-270^{\circ} \mathrm{C}\left(15{ }^{\circ} \mathrm{C} / \mathrm{min}\right)$; retention times $\left(t_{r}\right)$ are given in min. Analytical thin-layer chromatography (TLC) was carried out on ALUGRAM ${ }^{\circledR}$ Xtra SIL G UV ${ }_{254}$ aluminium sheets. Preparative thin-layer chromatography was carried on laboratory-made TLC glass plates with silica gel 60 $\mathrm{PF}_{254}$ (Merck). Column chromatography was performed using silica gel 60 of 40-60 microns (hexane/EtOAc as eluent). The tests for acetone determination using 2,4dinitrophenylhydrazine were carried out following a standard published procedure.

Typical procedure for the preparation of CuNPs/ZY $($ Method A) 
Anhydrous copper(II) chloride (135 mg, $1.0 \mathrm{mmol}$ ) was dissolved in dry THF or water $(15 \mathrm{~mL})$ and sodium Y zeolite $(1.28 \mathrm{~g})$ was added to the resulting solution. The mixture was stirred in the presence (for THF) or absence (for water) of argon overnight, followed by filtration and washing with THF or water $(20 \mathrm{~mL})$, and drying under vacuum (12 h).

\section{Typical procedure for the preparation of $\mathrm{CuNPs} / \mathrm{ZY}$ (Method B)}

Anhydrous copper(II) chloride (135 mg, $1.0 \mathrm{mmol})$ was added to a suspension of lithium powder (14 mg, 2.0 $\mathrm{mmol}$ ) and 4,4'-di-tert-butylbiphenyl (DTBB, $27 \mathrm{mg}, 0.1$ $\mathrm{mmol})$ in dry THF $(2 \mathrm{~mL})$ at room temperature under an argon atmosphere. The reaction mixture, which was initially dark blue, rapidly changed to black, indicating that the suspension of copper nanoparticles was formed. This suspension was diluted with THF $(18 \mathrm{~mL})$ followed by the addition of sodium $\mathrm{Y}$ zeolite $(1.28 \mathrm{~g})$. The resulting mixture was stirred for $1 \mathrm{~h}$ at room temperature, filtered, and the solid successively washed with $\mathrm{MeOH}(5 \mathrm{~mL})$ and THF (20 mL), and dried under vacuum $(5 \mathrm{~h})$.

\section{Typical procedure for the preparation of $\mathrm{CuNPs} / \mathrm{ZY}$ (Method C)}

Following the impregnation method $\mathrm{A}$, the resulting solid was added to a suspension of lithium powder $(14 \mathrm{mg}, 2.0$ mmol) and 4,4'-di-tert-butylbiphenyl (DTBB, $27 \mathrm{mg}, 0.1$ $\mathrm{mmol})$ in THF (2 mL) at room temperature under an argon atmosphere. The resulting mixture was stirred for $1 \mathrm{~h}$ at room temperature, filtered, and the solid successively washed with $\mathrm{MeOH}(5 \mathrm{~mL})$, THF $(20 \mathrm{~mL})$ and dried under vacuum $(12 \mathrm{~h})$.

General procedure for the CDC of tertiary amines and terminal alkynes catalyzed by CuNPs/ZY

The amine $(1,1.0 \mathrm{mmol})$, the alkyne $(2,1 \mathrm{mmol})$ and $t$ $\mathrm{BuOOH}-\mathrm{H}_{2} \mathrm{O}(2.0 \mathrm{mmol})$ were added to a reactor tube containing CuNPs/ZY (50 mg, $1.5 \mathrm{~mol} \%$ ) under air. The reaction mixture was warmed to $70{ }^{\circ} \mathrm{C}$ and stirred at that temperature for $15-20 \mathrm{~h}$. The resulting mixture was diluted with EtOAc $(15 \mathrm{~mL})$, filtered through Celite and subjected to column chromatography ( silica gel, hexane-EtOAc) to give the pure propargylamines 3 . The catalyst could be recovered by diluting the reaction crude with EtOAc (15 $\mathrm{mL})$, followed by centrifugation $(2500 \mathrm{rpm}, 15 \mathrm{~min})$, catalyst separation and washing (EtOAc, $15 \mathrm{~mL}$ ), and final drying under vacuum.

\section{Acknowledgements}

This work was generously supported by the Spanish Ministerio de Economía y Competitividad (MINECO; CTQ2011-24151). Y. M. acknowledges the Instituto de Síntesis Orgánica (ISO) of the Universidad de Alicante for a grant.

\section{References}

[1] a) F. Xiao, Y. Chen, Y. Liu, J. Whang, Tetrahedron 2008, 64, 2755-2761; b) D. Shibata, E. Okada, J. Molette, M. Médebielle, Tetrahedron Lett. 2008, 49, 7161-7164; c) Y. Yamamoto, H. Hayashi, T. Saigoku, H. Nishiyama, J. Am. Chem. Soc. 2005, 127, 1080410805; d) D. F. Harvey, D. M. Sigano, J. Org. Chem.
1996, 61, 2268-2272; e) B. Yan, Y. Liu, Org. Lett. 2007, 9, 4323-4326; f) E.-S. Lee, H.-S. Yeom, J.-H. Hwang, S. Shin, Eur. J. Org. Chem. 2007, 3503-3507.

[2] See, for instance: a) C. Jiang, M. Xu, S. Wang, H. Wang, Z.-J. Yao, J. Org. Chem. 2010, 75, 4323-4325; b) F. J. Fañanás, T. Arto, A. Mendoza, F. Rodríguez, Org. Lett. 2011, 13, 4184-4187; c) T. S. Symeonidis, M. G. Kallitsakis, K. E. Litinas, Tetrahedron Lett. 2011, 52, 5452-5455; d) Y. L. Zhao, C.-H. Di, S.-D. Liu, J. Meng, Q. Liu, Adv. Synth. Catal. 2012, 354, 35453550; e) H. V. Wachenfeldt, F. Paulsen, A. Sundin, D. Strand, Eur. J. Org. Chem. 2013, 4578-3550; d) B. Alcaide, P. Almendros, J. M. Alonso, I. Fernández, G. G. Campillos, M. R. Torres, Chem. Commun. 2014, 50, 4567-4567.

[3] See, for instance: a) A. Hoepping, K. M. Johnson, C. George, J. Flippen-Anderson, A. P. Kozikowski, J. Med. Chem. 2000, 43, 2064-2071; b) B. Jiang, M. Xu, Angew. Chem. Int. Ed. 2004, 43, 2543-2546; c) J. J. Fleming, J. Du Bois, J. Am. Chem. Soc. 2006, 128, 3926-3927.

[4] See, for instance: a) O. Bar-Am, T. Amit, O. Weinreb, M. B. H. Youdim, S. Mandel, J. Alheimer's Dis. 2010, 21, 361-371; b) I. Bolea, A. Gella, M. Unzeta, J. Neural Transm. 2013, 120, 893-902; c) J. Louvel, J. F. S. Carvalho, Z. Yu, M. Soethoudt, E. B. Lenselink, E. Klaase, J. Brussee, A. P. IJzerman, J. Med. Chem. 2013, 56, 9427-9440.

[5] a) C. W. Olanow, Neurology 2006, 66, S69-S79; b) M. Naoi, W. Maruyama, H. Yi, Y. Akao, Y. Yamaoka, M. Shamoto-Nagai, J. Neural Transm. 2007, 72, 121-131; c) Review: V. Oldfield, G. M. Keating, C. M. Perry, Drugs 2007, 67, 1725-1747; d) D. L. Murphy, F. Karoum, D. Pickar, R. M. Cohen, S. Lipper, A. M. Mellow, P. N. Tariot, T. Sunderland J. Neural Transm. Suppl. 1998, 52, 39-48.

[6] a) I. E. Kopka, Z. A. Fataftah, M. W. Rathke, J. Org Chem. 1980, 45, 4616-4622; b) S. Czernecki, J.-M. Valéry, J. Carbohydr. Chem. 1990, 9, 767-770; c) I. Imada, M. Yuasa, I. Nakamura, S.-I. Murahashi, J. Org. Chem. 1994, 59, 2282-2284.

[7] For reviews, see: a) R. Bloch, Chem. Rev. 1998, 98, 1407-1438; b) V. V. Kouznetsov, L. Y. Vargas Méndez, Synthesis 2008, 491-506; c) G. Blay, A. Monleón, J. R. Pedro, Curr. Org. Chem. 2009, 13, 1498-1539; see also: d) C. Fischer, E. M. Carreira, Org. Lett. 2001, 3, 4319-4321; e) C. Fischer, E. M. Carreira, Org. Lett. 2004, 6, 1497-1499.

[8] For reviews, see: a) C. Wei, Z. Li, C.-J. Li, Synlett 2004, 1472-1483; b) L. Zani, C. Bolm, Chem. Commun. 2006, 4263-4275; c) C.-J. Li, Acc. Chem. Res. 2010, 43, 581-590; d) W.-J. Yoo, L. Zhao, C.-J. Li, Aldrichimica Acta 2011, 44, 43-51; d) W.-J Yoo, L. Zhao, C.-J. Li In Science of Synthesis (Ed. T. J. Mueller), Thieme, Stuttgart, 2014, 1, 189-217.

[9] a) X. Xu, Z. Ge, D. Cheng, X. Li, ARKIVOC 2012, viii, 107-118; b) X. Chen, T. Chen, Y. Zhou, C.-T. Au, L.- 
B. Han, S.-F. Yin, Org. Biomol. Chem. 2014, 12, 247250.

[10] For reviews and monographs, see: a) C.-J. Li, Acc. Chem. Res. 2009, 42, 335-344; b) C. J. Scheuermann, Chem. Asian J. 2010, 5, 436-451; c) C. S. Yeung, V. M. Dong, Chem. Rev. 2011, 111, 1215-1292; d) F. W. Patureau, J. Wencel-Delord, F. Glorius, Aldrichim. Acta 2012, 45, 31-41; e) G. J. Deng, C.-J. Li In Organic Chemistry. Breakthoughs and Perspectives (Eds. K. Ding, L.-X. Dai), Wiley-VCH, Weinheim, 2012, chapter 19; f) From $C-H$ to $C-C$ Bonds: CrossDehydrogenative-Coupling (Ed. C.-J. Li), RSC, Cambridge (UK), 2015.

[11] a) Z. Li, C.-J. Li, J. Am. Chem. Soc. 2004, 126, 11810-11811; b) Z. Li, C.-J. Li, Org. Lett. 2004, 6, 4997-4999; c) Z. Li, P. D. MacLeod, C.-J. Li, Tetrahedron: Asymmetry 2006, 17, 590-597; d) Z. Li, D. S. Bohle, C.-J. Li, Proc. Natl. Acad. Sci. 2006, 103, 8928-8933; e) L. Zhao, C.-J. Li, Angew. Chem. Int. Ed. 2008, 47, 7075-7078.

[12] a) M. Niu, Z. Yin, H. Fu, Y. Jiang, Y. Zhao, J. Org. Chem. 2008, 73, 3961-3963; b) for an example using tertiary amine $N$-oxides, see: Z. Xu, X. Yu, X. Feng, M. Bao, J. Org. Chem. 2011, 76, 6901-6905.

[13] a) C. M. Rao Volla, P. Vogel, Org. Lett. 2009, 11, 1701-1704; b) Q. Shen, L. Zhang, Y.-R. Zhou, J.-X. Li, Tetrahedron Lett. 2013, 54, 6735-6728.

[14] X. Jin, K. Yamaguchi, N. Mizuno, RSC Adv. 2014, 4, 34712-34715.

[15] a) M. Rueping, R. M. Koenigs, K. Poscharny, D. C. Fabry, D. Leonori, C. Vila, Chem. Eur. J. 2012, 18, 5170-5174; b) D. B. Freeman, L. Furst, A. G. Condie, C. R. J. Stephenson, Org. Lett. 2012, 14, 94-97; c) I. Perepichka, S. Kundu, Z. Hearne, C.-J. Li, Org. Biomol. Chem. 2015, 13, 447-451.

[16] a) A. Arroyo, Coupling of Amines and Alkynes Catalyzed by Supported Copper Nanoparticles, Master's Degree, Universidad de Alicante, 2013; b) M. I. Martín García, Cross-Dehydrogenative Coupling Catalyzed by Copper Nanoparticles on Zeolite for the Synthesis of Propargylic Amines, Master's Degree, Universidad de Alicante, 2015.

[17] a) R. Hudson, S. Ishikawa, C.-J. Li, A. Moores, Synlett 2013, 24, 1637-1642 (10 mol\% $\mathrm{CuFe}_{2} \mathrm{O}_{4}, 1$ equiv. DDQ, decane, $100{ }^{\circ} \mathrm{C}$ ); b) G. H. Dang, D. T. Nguyen, D. T. Le, T. Truong, N. T. S. Phan, J. Mol. Catal. A: Chem. 2014, 395, 300-306 (2 equiv. N, Ndimethylaniline, 5\% MOF-199, 3 equiv. TBHP, DMA, $\left.120^{\circ} \mathrm{C}, \mathrm{Ar}\right)$.

[18] For selected reviews and monographs, see: a) Nanoparticles and Catalysis (Ed.: D. Astruc), WileyVCH, Weinheim, 2008; b) M. Kidwai, in Handbook of Green Chemistry, Vol. 2 (Eds.: P. T. Anastas, R. H. Crabtree), Wiley-VCH, Weinheim, 2009, pp. 81-92; c) N. Yan, C. Xiao, Y. Kou, Coord. Chem. Rev. 2010, 254, 1179-1218; d) V. Polshettiwar, R. S. Varma, Green Chem., 2010, 12, 743-754; e) Selective Nanocatalysts and Nanoscience (Eds.: A. Zecchina, S. Bordiga, E.
Groppo), Wiley-VCH, Weinheim, 2011; f) V. Polshettiwar, R. Luque, A. Fihri, H. Zhu, M. Bouhara, J.-M. Basset, Chem. Rev. 2011, 111, 3036-3075; g) Nanocatalysis: Synthesis and Applications (Eds.: V. Polshettiwar, T. Asefa), John Wiley \& Sons, Hoboken (NJ), 2013; h) Nanomaterials in Catalysis (Eds.: P. Serp, K. Philippot), Wiley-VCH, Weinheim, 2013; i) Metal Nanoparticles for Catalysis: Advances and Applications (Ed.: F. Tao), RSC, Cambridge, 2014.

[19] For reviews, see: a) F. Alonso, G. Radivoy, M. Yus, Russ. Chem. Bull. 2003, 52, 2563-2576; b) F. Alonso, M. Yus, Chem Soc. Rev. 2004, 33, 284-293; c) F. Alonso, M. Yus, Pure Appl. Chem. 2008, 80, 10051012; d) F. Alonso, P. Riente, M. Yus, Acc. Chem. Res. 2011, 44, 371-391; e) F. Alonso in Metal Nanoparticles for Catalysis: Advances and Applications (Ed.: F. Tao), RSC, Cambridge, 2014, chapter 5, pp. 83-98.

[20] For selected examples, see: a) F. Alonso, T. Melkonian, Y. Moglie, M. Yus, Eur. J. Org. Chem. 2011, 2524-2530 (alkyne homocoupling); b) M. J. Albaladejo, F. Alonso, Y. Moglie, M. Yus, Eur. J. Org. Chem. 2012, 3093-3104 (A $\mathrm{A}^{3}$ coupling); c) F. Alonso, Y. Moglie, G. Radivoy, M. Yus, J. Org. Chem. 2013, 78, 5031-5037 (click chemistry); d) M. J. Albaladejo, F. Alonso, M. Yus, Chem. Eur. J. 2013, 19, 5242-5245 (indolizine and chalcone synthesis).

[21] a) F. Alonso, J. J. Calvino, I. Osante, M. Yus, Chem. Lett. 2005, 34, 1262-1263; b) F. Alonso, J. J. Calvino, I. Osante, M. Yus, J. Exp. Nanosci. 2006, 1, 419-433.

[22] Other oxidants such as $\mathrm{H}_{2} \mathrm{O}_{2}, \mathrm{~K}_{2} \mathrm{~S}_{2} \mathrm{O}_{8}, \mathrm{O}_{2}$, oxone, $\mathrm{DDQ}, \mathrm{PhI}(\mathrm{OAc})_{2}$ or $\mathrm{I}_{2}$ were found to be inefficient in this transformation.

[23] a) A. S. Kovo, O. Hernandez, S. M. Holmes, J. Mater. Chem. 2009, 19, 6207-6212; b) K. V. R. Chary, G. V. Sagar, C. S. Srikhanth, V. V. Rao, J. Phys. Chem. B. 2007, 111, 543-550; c) J. Giménez-Mañogil, A. Bueno-López, A. García-García, Appl. Catal. B: Environ. 2014, 152-153, 99-107.

[24] a) A. T. Nguyen, L. T. Pham, N. T. S. Phan, T. Truong, Catal. Sci. Technol. 2014, 4, 4281-4288; b) G. H. Dang, T. T. Dang, D. T. Le, T. Truong, N. T. S. Phan, J. Catal. 2014, 319, 258-264.

[25] Q. Shen, L. Zhang, Y.-R. Zhou, J.-X. Li, Tetrahedron Lett. 2013, 54, 6725-6728.

[26] Reviews: a) D. Astruc, F. Lu, J. Ruiz Aranzaes, Angew. Chem. Int. Ed. 2005, 44, 7852-7872; b) L. Durán Pachón, G. Rothenberg, Appl. Organomet. Chem. 2008, 22, 288-299.

[27] M. R. Decan, S. Impellizzeri, M. L Marin, J. C. Scaiano, Nat. Commun. 2014, 5, 4612.

[28] For a perspective on heterogeneous catalytic homocoupling of terminal alkynes, see: F. Alonso, M. Yus, ACS Catal. 2012, 2, 1441-1451.

[29] For an excellent revision on the mechanism of the CDC, see: A. S.-K. Tsang, S. J. Park, M. H. Todd in From $\mathrm{C}-\mathrm{H}$ to $\mathrm{C}-\mathrm{C}$ Bonds: Cross-Dehydrogenative- 
Coupling (Ed. C.-J. Li), RSC, Cambridge (UK), 2015, chapter 11, pp. 254-294.

[30] W. H. Richardson, J. Am. Chem. Soc. 1965, 87, 247253.

[31] D. E. Diaz-Droguett, R. Espinoza, V. M. Fuenzalida, Appl. Surf. Sci. 2011, 257, 4597-4602.

[32] F. Alonso, Y. Moglie, G. Radivoy, M. Yus, J. Org. Chem. 2011, 76, 8394-8405.

[33] G.-J. Cheng, L.-J. Song, Y.-F. Yang, X. Zhang, O Wiest, Y.-D. Wu, ChemPlusChem 2013, 78, 943-951.

[34] C.-K. Chen, A. G. Hortmann, M. R. Marzabadi, J. Am. Chem. Soc. 1988, 110, 4829-4831. 


\section{FULL PAPER}

Cross-Dehydrogenative Coupling of Tertiary Amines and Terminal Alkynes Catalyzed by Copper Nanoparticles on Zeolite

Adv. Synth. Catal. Year, Volume, Page - Page

Francisco Alonso,* Adrián Arroyo, Iris MartínGarcía and Yanina Moglie

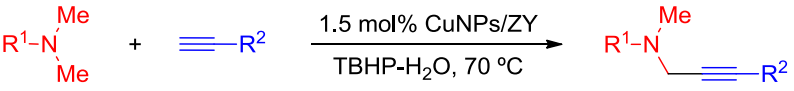

$$
\begin{aligned}
& \text { - no solvent 43-98\% } \\
& \text { - in air (16 examples) } \\
& \begin{array}{ll}
\mathrm{R}^{1}=\text { aryl, alkyl } & \text { - in air } \\
\mathrm{R}^{2}=\text { aryl, alkyl, } \mathrm{CO}_{2} \mathrm{Et} & \text { - reusable catalyst }
\end{array}
\end{aligned}
$$

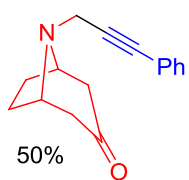

